\title{
Nitrate-Reducing Magnetic Hybrid Coagulant for Rapid and Advanced Wastewater Treatment and its Mechanistic Investigation
}

\author{
Yang $\mathrm{He}^{1}$, Jin-Wei Liu ${ }^{1}$, Si Chen ${ }^{1}$, Si-Tong Liu ${ }^{2}$, and Hua-Zhang Zhao ${ }^{1}$ \\ ${ }^{1}$ Peking University \\ ${ }^{2}$ Qinghai University
}

July 7, 2020

\begin{abstract}
Dissolved contaminants $\left(\mathrm{NO}_{3}{ }^{-}-\mathrm{N}\right.$, etc. $)$ in municipal sewage effluent and polluted water resources need to be further removed, but common advanced water treatment technologies usually have unsatisfactory performance and large process footprints. Magnetic seeding coagulation (MSC) has a rapid settling speed; however, it is less effective for removing dissolved contaminants and cannot recovers effective components. Herein, a novel covalently bound magnetic hybrid coagulant (MHC) was synthesized and used to treat secondary biological effluent. MHC settling time was $2 / 3$ shorter than traditional MSC and showed high removal efficiencies for conventional coagulation indicators and dissolved contaminants such as $\mathrm{NO}_{3}{ }^{-}-\mathrm{N}$ and organic nitrogen. The $\mathrm{NO}_{3}{ }^{-}-\mathrm{N}$ removal mechanisms included $\mathrm{NO}_{3}{ }^{-} \mathrm{N}$ capture through the electrostatic attraction and the collision efficiency enhancement. MHC integral structure can be bioregenerated for multiple cycles. Because of its effectiveness in removing dissolved contaminants rapidly, MHC has potential application in advanced water treatment, especially in land-scarce areas.
\end{abstract}

\section{Introduction}

When municipal sewage and polluted natural waters have been treated by aerobic biological techniques, some dissolved contaminants such as nitrogen, phosphorus, and organic pollutants will not be fully removed and thus remain in the effluent. ${ }^{1}$ Nitrogen-containing contaminants mainly exist in the form of $\mathrm{NO}_{3}{ }^{-}-\mathrm{N} .{ }^{2}$ After being discharged into natural water bodies, these contaminants may pose a threat to ecological safety and human health. ${ }^{3}$ Advanced water treatment technologies including biological denitrification, ${ }^{4}$ adsorption, ${ }^{5}$ and ion exchange ${ }^{6}$ usually exhibit unsatisfactory removal efficiencies and occupy a large land area. In many urban areas, high population density leaves almost no space to adopt additional advanced water treatment technologies. Therefore, developing a small-footprint, effective water treatment technology is required to control water pollution in urban areas.

Coagulation is one of the most widely-used technologies for conventional water treatment and is also the basis for some of the most-preferred advanced treatment processes. ${ }^{7}$ Magnetic seeding coagulation (MSC) has attracted attention because it settles faster than conventional coagulations, ${ }^{8}$ resulting in smaller treatment footprints. MSC is generally carried out by adding magnetic seeds (usually $\mathrm{Fe}_{3} \mathrm{O}_{4}$ particles), inorganic coagulants (polyaluminum salt/polyferric salt), and/or organic polymer flocculants (usually polyacrylamide) to water. ${ }^{9}$ Contaminants, coagulants, and magnetic seeds mix to form magnetic flocs, which quickly aggregate and precipitate with an applied magnetic field. The magnetic seeds can be recovered after magnetic separation. ${ }^{10}$ Similar to conventional coagulation, MSC can effectively remove particulate and colloidal pollutants, but it shows lower efficacy in removing dissolved contaminants with higher risks, including $\mathrm{NO}_{3}{ }^{-} \mathrm{N}$ and dissolved organic nitrogen (DON). ${ }^{11,} 12$

In our previous work, we prepared inorganic-organic covalently bound hybrid coagulants with a capacity to remove typical dissolved contaminants by introducing organic groups into inorganic coagulants. ${ }^{13,}{ }^{14}$ If 
special functional groups can be introduced into magnetic seeding components, the novel magnetic coagulants have the potential to remove dissolved contaminants that are difficult to be removed by conventional coagulants. Covalent bonds between magnetic components and coagulants are beneficial because they form tighter magnetic flocs, which precipitate more easily and further shorten the settling time. In addition, the integral magnetic coagulants can be recovered, overcoming the disadvantage of MSC, which can recover the magnetic seeds and not the coagulants (Figure 1).

In this study, we synthesized a novel inorganic-organic covalently bound magnetic hybrid coagulant (MHC) in one step by using silane coupling agents with quaternary ammonium groups and iron salts. Secondary biological effluent was used as raw water to test the performance of MHC. We focused on removal efficacy and mechanism of nitrogen-containing contaminants, including $\mathrm{NO}_{3}{ }^{-}-\mathrm{N}$ and DON. The $\mathrm{NO}_{3}{ }^{-}-\mathrm{N}$ adsorption site and removal pathway were elucidated by molecular dynamics (MD) simulations. The effect of applied magnetic field strength on $\mathrm{NO}_{3}{ }^{-}-\mathrm{N}$ removal was modeled using MATLAB (MathWorks, Natick, MA, USA). The feasibility of MHC recovery and regeneration was also explored.

\section{Experimental Section}

Materials

Secondary biological effluent and synthetic aqueous solution were used in experiments. More details are in the Supporting Information (SI). Ferric chloride $\left(\mathrm{FeCl}_{3} \cdot 6 \mathrm{H}_{2} \mathrm{O}\right)$, ferrous chloride $\left(\mathrm{FeCl}_{2} \cdot 4 \mathrm{H}_{2} \mathrm{O}\right)$, polyferric chloride (PFC), polyacrylamide (PAM), ferroferric oxide $\left(\mathrm{Fe}_{3} \mathrm{O}_{4}\right)$, potassium nitrate $\left(\mathrm{KNO}_{3}\right)$, and potassium sulfate $\left(\mathrm{K}_{2} \mathrm{SO}_{4}\right)$ were obtained from Sigma-Aldrich (St. Louis, USA). 3-(trimethoxysilyl) propyl- $n$ -octadecyldimethyl ammonium chloride (TPODAC) was purchased from Bailingwei (Beijing, China). Potassium dihydrogen phosphate $\left(\mathrm{KH}_{2} \mathrm{PO}_{4}\right)$ was purchased from Macklin (Shanghai, China).

MHC synthesis

MHC was synthesized by combining co-precipitation and slow alkalinity titration method into one step. First, $150 \mathrm{~mL}$ deionized water was added to a three-necked flask and deoxygenated by bubbling $\mathrm{N}_{2}$ gas for $5 \mathrm{~min}$. Under a nitrogen atmosphere, $32.5 \mathrm{~g} \mathrm{FeCl}_{3} \cdot 6 \mathrm{H}_{2} \mathrm{O}$ and $4.8 \mathrm{~g} \mathrm{FeCl}_{2} \cdot 4 \mathrm{H}_{2} \mathrm{O}$ were added, and the mixture was stirred at room temperature for $5 \mathrm{~min}$ until dissolved. Then the mixture was gradually heated to 80 , and TPODAC was added at the $\mathrm{Si} / \mathrm{Fe}$ molar ratio of $1 / 6$. The mixture was titrated by $1 \mathrm{~mol} / \mathrm{L} \mathrm{NaOH}(270 \mathrm{~mL})$ for $3 \mathrm{~h}$ under rapid stirring. After cooling to room temperature, the product aged for $12 \mathrm{~h}$ to obtain MHC.

Jar tests

Coagulation performance was evaluated using a programmable TA6-1 jar test apparatus (Wuhan, China). MHC or conventional coagulants were added to raw water, mixed rapidly at $250 \mathrm{rpm}$ for $1.5 \mathrm{~min}$, mixed slowly at $50 \mathrm{rpm}$ for $20 \mathrm{~min}$, and settled for $30 \mathrm{~min}$ with applied magnetic field. For $\mathrm{MSC}, \mathrm{Fe}_{3} \mathrm{O}_{4}$ and $\mathrm{PFC}$ were added before stirring, and PAM was added after rapid mixing. During the settling period, samples were collected from $2 \mathrm{~cm}$ below the water surface at regular intervals. Turbidity was analyzed, and then samples were filtered through $0.22 \mu \mathrm{m}$ nylon membrane filters before analyzing $\mathrm{TP}, \mathrm{NO}_{3}{ }^{-}-\mathrm{N}, \mathrm{UV}_{254}$, dissolved organic matter (DOM), and N-containing compounds in DOM. The secondary biological effluent was used to explore the coagulation performance, and the synthetic aqueous solution was used to evaluate factors affecting coagulation.

\section{Analytical methods}

The morphology and chemical structure of MHC were analyzed by transmission electron microscopy (TEM; Hitachi, H-9000NAR, Tokyo, Japan) and Fourier-transform infrared spectroscopy (FTIR; Nicolet iS50, Madison , USA), respectively. TP, $\mathrm{NO}_{3}{ }^{-}-\mathrm{N}$, and $\mathrm{UV}_{254}$ were determined by an ultraviolet-visible 1800 spectrophotometer (Shimadzu, Kyoto, Japan). Turbidity was measured by a turbidimeter (2100 N Turbidimeter, Hach, Loveland, USA). To measure DOM and DON concentration and type in the coagulated water by MHC, a Bruker Apex (Madison, USA) ultra Fourier-transform ion cyclotron resonance mass spectrometer (FT-ICR MS) equipped with a 9.4 T superconducting magnet was used. More details are in SI. 


\section{MD simulations}

Partial charges for $\mathrm{MHC}$ atoms and $\mathrm{NO}_{3}$-ions were obtained from density functional theory (DFT) calculations using Gaussian 09 program. The Becke three parameters hybrid exchange-correlation functional (B3LYP $)^{15}$ and the standard Gaussian-type basis set 6-311 $\mathrm{G}^{*}$ were employed. All other force field parameters for atoms were extracted from PLOS-AA force field ${ }^{16}$. The initial configuration was solvated into a cubic water box with $63 \AA$ on each side, containing 8,000 water molecules. The simple point charge (SPC) water model as explicit solvent was used for solvation ${ }^{17}$. Then $15 \mathrm{Cl}^{-}$were added to balance system charges. The system energy was minimized for 500 steps using steepest descending method. The initial velocities were assigned to produce a Maxwell distribution at $298 \mathrm{~K}$. After a $0.2 \mathrm{~ns}$ equilibrium, a $1 \mathrm{~ns}$ simulation was carried out with the $\mathrm{NO}_{3}{ }^{-}$ion frozen so that the MHC carbon chains would reach a balance. Finally, this system perform a $3 \mathrm{~ns}$ MD simulation. More details are in the SI.

\section{MHC bioregeneration}

Donnan dialysis coupled with bio-denitrification was used to regenerate MHC. Before bioregeneration, MHC was saturated by $\mathrm{NO}_{3}{ }^{-}-\mathrm{N}$ in repeated coagulation processes. Then the bioregeneration was carried out at room temperature and under anaerobic conditions in a Donnan dialysis setup. The setup was made of Plexiglas (Beijing, China), divided into two chambers by a JAM-I homogeneous anion exchange membrane. The spent MHC was added into the desorption chamber. Sludge, $0.3 \mathrm{~mol} / \mathrm{L} \mathrm{NaCl}$, and $12.9 \mathrm{~mol} / \mathrm{L}$ ethanol (as carbon source) were added to the stripping chamber. The solution $\mathrm{pH}$ in both chambers was adjusted to 7.0 \pm 0.2 . The solution was stirred continuously at $400 \mathrm{rpm}$. Throughout the $30 \mathrm{~h}$ regeneration process, samples were collected at regular intervals from both chambers and filtered through $0.22 \mu \mathrm{m}$ nylon membranes for analysis of residual $\mathrm{NO}_{3}{ }^{-}-\mathrm{N}$. The sludge cultivation method is in the SI.

\section{Results and Discussion}

MHC synthesis and characterization

The MHC synthesis steps and structure are shown in Figure 2. Briefly, the organic-inorganic covalently bound MHC was synthesized in one step by mixing $\mathrm{Fe}^{3+}, \mathrm{Fe}^{2+}$, and silane coupling agents in proportion, slowly titrating alkalinity, and ageing. The TEM image (Figure 3a) shows that MHC has an irregular shape. Comparing to the $\mathrm{Fe}_{3} \mathrm{O}_{4}$ TEM image (Figure 3b), it can be seen that the black component in $\mathrm{MHC}$ is $\mathrm{Fe}_{3} \mathrm{O}_{4}$. The periphery of $\mathrm{Fe}_{3} \mathrm{O}_{4}$ is the highly-crosslinked polymer of the organic silane coupling agent. It shows that MHC is a cross-linked integral structure consisting of magnetic components and organic compounds.

The presence of silane coupling agents will form Si-O-Si bonds. Generally, the asymmetric stretching peak of Si-O-Si is at $1046 \mathrm{~cm}^{-1} .{ }^{18}$ Shown in the infrared absorption spectrum of MHC (Figure 3c), there is a clear absorption peak at $1028 \mathrm{~cm}^{-1}$. It may be related to red shift of the Si-O characteristic peak induced by Fe replacing $\mathrm{Si}$ in $\mathrm{Si}-\mathrm{O}-\mathrm{Si} .{ }^{19}$ This indicates that the inorganic Fe components in $\mathrm{MHC}$ are coupled to organic components through covalent bonds of Si-O-Fe, which is different from MSC that simply physically mixes magnetic seeds and coagulants. Other absorption wavenumbers are listed in Table S1. In addition, MHC has a high zeta potential $(>25 \mathrm{mV})$ over a wide $\mathrm{pH}$ range of 3-11 (Figure S1), which can be attributed to the introduction of positively-charged quaternary ammonium groups.

Coagulation performance

Secondary biological effluent from a municipal wastewater treatment plant was used as raw water (the raw water quality is shown in Table S2) to test the coagulation performance. The MHC settling time (5 min) was shorter than conventional coagulations $\left(20 \mathrm{~min}\right.$ ) (Figure S2, close to previous reported results ${ }^{8,20}$ ). The MHC settling time was also shorter than MSC (15 min), especially for $\mathrm{UV}_{254}, \mathrm{TP}$, and $\mathrm{NO}_{3}{ }^{-}-\mathrm{N}$ (Figure $4 \mathrm{~b}$, $\mathrm{c}, \mathrm{d}$ ). The settling time of the two coagulants for turbidity removal is similar, which is because particulate contaminants are easier to aggregate into large complexes and can quickly precipitate under gravity. The rapid settling speed of MHC can be attributed to the covalent bonds between magnetic components and coagulants. Magnetic flocs formed when MHC combined with contaminants, which settled rapidly by both magnetic force and gravity. Moreover, the MHC flocs have higher density, which are easier to settle than 
flocs formed by physical mixing. For MSC, however, the lack of covalent bonds means some flocs are not combined with magnetic seeds. These flocs have smaller density and can only settle slowly by gravity rather than by magnetic force.

Turbidity removal was high for both MHC and MSC (>97.1\%) (Figure 4a). For UV $_{254}$ and TP (Figure 4b, c), removal efficiency was much higher with $\mathrm{MHC}\left(78.3 \%\right.$ for $\mathrm{UV}_{254}, 98.8 \%$ for TP and from $0.55 \mathrm{mg} / \mathrm{L}$ to $0.0065 \mathrm{mg} / \mathrm{L})$ than MSC $\left(67.5 \%\right.$ for $\mathrm{UV}_{254}, 78.2 \%$ for TP and from $0.55 \mathrm{mg} / \mathrm{L}$ to $\left.0.12 \mathrm{mg} / \mathrm{L}\right)$. The TP removal efficiency by MSC was relatively low, which may be related to the low initial TP concentration. More importantly, MSC (Figure 4d) and conventional coagulations (Figure S2) were comparatively ineffective for removing $\mathrm{NO}_{3}{ }^{-}-\mathrm{N}$, whereas $\mathrm{NO}_{3}{ }^{-}-\mathrm{N}$ concentration decreased from $11.3 \mathrm{mg} / \mathrm{L}$ to $3.1 \mathrm{mg} / \mathrm{L}(72.2 \%$ removal $)$ with MHC coagulation (Figure 4d). In conclusion, for contaminants that can be removed by traditional MSC, $\mathrm{MHC}$ had a higher removal efficiency and settling speed. MHC was also effective for removing contaminants that cannot be removed by conventional coagulations and traditional MSC (e.g., $\mathrm{NO}_{3}{ }^{-}-\mathrm{N}$ ).

We investigated DOM removal at the molecular level when using MHC. According to the element composition, DOM is divided into CHO, CHON, CHOS, and CHONS. After coagulation by MHC, above four types DOM decreased significantly, especially CHON compounds (Figure 5a). However, the relative abundance of CHON did not change obviously after conventional coagulants treatment (Figure S3). This shows that MHC is significantly different from conventional coagulants. MHC can remove DOM, especially DON that is resistant to conventional coagulants.

Van Krevelen diagrams ${ }^{21}$ (see the SI for the Van Krevelen diagram method) were applied to further elucidate the performance of MHC for removal of DON with different element ratios. Based on the $\mathrm{H} / \mathrm{C}$ and $\mathrm{O} / \mathrm{C}$ element ratios, DON can be divided into seven compound classes, including lipids (Lip), aliphatic/proteins (Ali/Pro), lignins/carboxylic rich alicyclic molecules-like (CRAM), carbohydrates (Car), unsaturated hydrocarbons (UH), aromatic (Aro), and tannin (Tan). DON in raw water was distributed centrally in the CRAM region (Figure 5b), and the relative abundance of CRAM was the highest (Figure 5d), indicating that these components had a high contribution to the DON in the raw water. Other researches have had similar results. $^{22,}{ }^{23}$ It may be related to CRAM's resistance to biodegradation and the refractory nature caused by the structural diversity found within CRAM and its substantial content of alicyclic rings and branching. ${ }^{24}$ However, the dots in the CRAM region disappeared partially after MHC coagulation (Figure 5c), and the relative abundance reduced by about $2 / 3$ (Figure $5 \mathrm{~d}$ ), revealing that MHC coagulation can effectively reduce the number of CRAM contaminants species and concentration of DON. Nitrogen-containing organic compounds are toxic, and various nitrogen compounds can be converted between each other, such as $\mathrm{NO}_{3}{ }^{-}-\mathrm{N}$ and DON. ${ }^{25,}{ }^{26} \mathrm{MHC}$ can effectively remove DON in water, reducing the possibility of DON transformation to $\mathrm{NO}_{3}{ }^{-}-\mathrm{N}$.

\section{Factors affecting nitrate removal}

We next studied influence factors in nitrate removal through MHC coagulation using synthetic aqueous solutions. The nitrate removal efficiency remained almost unchanged when initial $\mathrm{NO}_{3}{ }^{-} \mathrm{N}$ ranged from 15 to $25 \mathrm{mg} / \mathrm{L}$ (Figure 6a; all are above $69.2 \%$ ), demonstrating that MHC is suitable for the treatment of wastewater with varying pollutant concentrations. Across the $\mathrm{pH}$ range of $5-9$, there was no substantial effect on the $\mathrm{NO}_{3}{ }^{-}-\mathrm{N}$ removal efficiency (Figure $6 \mathrm{~b}$ ). When $\mathrm{pH}>10$, the removal efficiency decreased substantially (Figure $\mathrm{S} 4$ ), which can be attributed to the competing adsorption of $\mathrm{OH}^{-}$.

Using typical anions in natural water (i.e., sulfate and phosphate), we investigated the effect of competing ions on nitrate removal when using MHC. As molar ratio of sulfate and phosphate to $\mathrm{NO}_{3}{ }^{-}$increased, the $\mathrm{NO}_{3}{ }^{-}-\mathrm{N}$ removal efficiency gradually decreased (Figure 6c). To further quantify the effect of competition, the selectivity coefficient $K_{\mathrm{NO}_{3}^{-} / X^{n-}}$ (calculation formula is in SI) was applied to characterize the affinity of MHC to $\mathrm{NO}_{3}{ }^{-}$and coexisting ions. $\mathrm{K}$ values greater than one means that the affinity for $\mathrm{NO}_{3}{ }^{-}$is stronger than $X^{n-}$, lower than one means that the affinity for $\mathrm{NO}_{3}{ }^{-}$is weaker than $X^{n-}$. When phosphate and sulfate are present, the selectivity coefficients of $\mathrm{MHC}$ for $\mathrm{NO}_{3}{ }^{-}$are 3.19 and 0.77 respectively (Figure 6d), revealing that the affinity order of $\mathrm{MHC}$ for the three ions is phosphate $<$ nitrate $<$ sulfate. 
MHC has a stronger affinity for sulfate than nitrate. Sulfate contains more charges than nitrate, and the hydrated radius for sulfate $(0.300 \mathrm{~nm})^{27}$ is smaller than nitrate $(0.335 \mathrm{~nm})^{28}$, which are both beneficial for electrostatic interaction with quaternary ammonium. For the secondary biological effluent, the molar ratio of sulfate to nitrate is mostly lower than $1.5,{ }^{29-31}$ and the nitrate removal efficiency can still reach more than $65 \%$ (Figure 6c). Therefore, although sulfate will reduce nitrate removal to a certain extent when using MHC, sulfate has little effect on practical applications. MHC has weaker affinity for phosphate than nitrate, probably because phosphate Gibbs hydration energy $\left(-1125.3 \mathrm{~kJ} / \mathrm{mol}\right.$ for $\mathrm{HPO}_{4}{ }^{2-}$ and $-465 \mathrm{~kJ} / \mathrm{mol}$ for $\mathrm{H}_{2} \mathrm{PO}_{4}{ }^{-}$, the two main form of phosphate under neutral $\mathrm{pH}$ conditions $)^{32,} 33$ are lower than nitrate Gibbs hydration energy $(-306 \mathrm{~kJ} / \mathrm{mol})^{33}$. Thus phosphate only has a slight effect on the $\mathrm{NO}_{3}{ }^{-}-\mathrm{N}$ removal. In conclusion, MHC has strong adaptability to the change of water quality.

Removal pathway of nitrate by MHC

$\mathrm{NO}_{3}{ }^{-}$was taken as an example to explore the mechanism of dissolved contaminants removal by MHC using MD. First, the adsorption site was determined by the relationship between the total interaction potential $\left(V_{\text {total }}\right)$ and relative positions of $\mathrm{MHC}$ and $\mathrm{NO}_{3}{ }^{-}$. $\mathrm{NO}_{3}{ }^{-}$positions were classified into three categories according to $V_{\text {total }}$ : strongly attracted $\left(V_{\text {total }}<-80 \mathrm{~kJ} / \mathrm{mol}\right.$, purple dots in Figure 7a, configuration i in Figure $7 \mathrm{~b})$, weakly attracted $\left(-40 \mathrm{~kJ} / \mathrm{mol}<V_{\text {total }}<0\right.$, green dots in Figure $7 \mathrm{a}$, configuration ii in Figure $\left.7 \mathrm{~b}\right)$ and almost no interaction $\left(V_{\text {total }}=0\right.$, yellow dots in Figure $7 \mathrm{a}$, configuration iii in Figure $\left.7 \mathrm{~b}\right)$. It can be seen that $\mathrm{NO}_{3}{ }^{-}$that has strongest interaction with $\mathrm{MHC}$ was distributed around quaternary ammonium $\mathrm{N}$ atoms. The contact area with quaternary ammonium N atoms was large $\left(S_{\text {buried }}>1.5 \mathrm{~nm}^{2}\right)$ and the distance to the $\mathrm{N}$ plane was 0 (Figure 7a). However, $\mathrm{NO}_{3}{ }^{-}$have weak interaction with $\mathrm{MHC}$ were distributed around carbon chains. The above results show that the $\mathrm{N}$ atom of the positively-charged quaternary ammonium group is the main adsorption site, and the carbon chains only have very weak attraction to $\mathrm{NO}_{3}{ }^{-}$.

To investigate $\mathrm{NO}_{3}{ }^{-}$removal pathway and driving force, representative trajectory and time evolution of van der Waals (vdW) and electrostatic interaction energies between $\mathrm{NO}_{3}{ }^{-}$and quaternary ammonium $\mathrm{N}$ atom were analyzed. Electrostatic interaction energy changed rapidly with $\mathrm{NO}_{3}{ }^{-}$adsorption compared with vdW interaction energy (fluctuating at $\sim 0$ ), indicating that electrostatic attraction is the main driving force for adsorption. At $\mathrm{t}=1000 \mathrm{ps}$, the electrostatic interaction energy decreased, but it immediately increased and fluctuated at $\sim 0$ (Figure 7c), which suggests that the electrostatic interaction at 1000 ps was weak and unstable. Configuration i in Figure 7e illustrates that $\mathrm{NO}_{3}{ }^{-}$was outside the methyl groups of quaternary ammonium at $1000 \mathrm{ps}$, which hindered the interaction of positive $\mathrm{N}$ atom and $\mathrm{NO}_{3}{ }^{-}$.

After $\mathrm{t}=2000 \mathrm{ps}$, the electrostatic interaction energy decreased and stabilized at ${ }^{\sim}-100 \mathrm{~kJ} / \mathrm{mol}$ (Figure 7c). At the same time, hydrogen bonds between $\mathrm{NO}_{3}{ }^{-}$and coordinating water molecules decreased from 7.9 (before $2000 \mathrm{~ns}$ ) to $~ 6.7$ (after $2000 \mathrm{~ns}$ ) (Figure 7d), indicating $\mathrm{NO}_{3}{ }^{-}$dehydrates during adsorption. As shown in Figure 7e, $\mathrm{NO}_{3}{ }^{-}$will first adjust its configuration to enter into the methyl groups (Configuration ii) and then will interact closely with the quaternary ammonium $\mathrm{N}$ atom (Configuration iii) to achieve stable adsorption. The above results revealed that during $\mathrm{NO}_{3}{ }^{-}$removal, $\mathrm{NO}_{3}{ }^{-}$will dehydrate and penetrate methyl groups of quaternary ammonium and interact strongly with quaternary ammonium $\mathrm{N}$ atom by electrostatic attraction.

Removal mechanism by magnetic components

With the magnetic field, $\mathrm{NO}_{3}{ }^{-}-\mathrm{N}$ removal was $71.3 \%$, while without magnetic field, $\mathrm{NO}_{3}{ }^{-}-\mathrm{N}$ removal was $58.1 \%$ (Figure 8a). The mechanism of enhancing $\mathrm{NO}_{3}{ }^{-}-\mathrm{N}$ removal under magnetic field was explored using MATLAB. When the distance between magnetic particles was constant, the greater the applied magnetic field intensity, the greater the interaction potential. Furthermore, the interaction potential between magnetic particles with magnetic field was five orders of magnitude higher than that without magnetic field (Figure 8b). Without magnetic field, the particle interactions are only vdW and electrostatic. With the applied magnetic field, an additional magnetic interaction is generated among magnetic particles ${ }^{34}$, which increases the total interaction potential. According to the collision efficiency formula and the classical flocculation model (SI), the higher the interaction potential, the higher the interparticle collision efficiency $\alpha_{\mathrm{ij}}$ and the 
coagulation efficiency. ${ }^{35}$ Therefore, the applied magnetic field can increase the interaction potential between particles, thereby enhancing the contaminant removal when using MHC.

MHC bioregeneration

Donnan dialysis combined with bio-denitrification was applied to regenerate MHC (Figure 9a). Donnan dialysis (the principles are in SI) is a process that promotes migration of target ions across a membrane. ${ }^{36}$ The transport of target ions is promoted by the electrochemical potential gradient caused by the ion composition on both sides of the membrane, while the transfer of co-ions is prevented by the ion exchange membrane. As shown in Figure $9 \mathrm{~b}$ and $\mathrm{c}$, during the regeneration process, the $\mathrm{NO}_{3}{ }^{-}-\mathrm{N}$ concentration in the two chambers first increased, then decreased after $\sim 5$ hours, and reached equilibrium after 10 hours. It shows that $\mathrm{NO}_{3}{ }^{-}$was firstly desorbed from the MHC into the desorption solution, then transported across the membrane to the stripping solution driven by the electrochemical potential produced by $\mathrm{NaCl}$, and finally denitrified by microorganisms. After three cycles of coagulation and regeneration, the $\mathrm{NO}_{3}{ }^{-}-\mathrm{N}^{-}$removal using MHC decreased from $72.2 \%$ to $61.8 \%$ (Figure 9d). This shows that the Donnan dialysis combined with bio-denitrification method can be used for MHC multiple regeneration cycles without significant reduction in contaminants removal efficiency. The method minimizes chemical reagent use and does not generate secondary high-concentration wastewater. The ion exchange membrane separates microorganisms from flocs, thereby preventing the microorganisms from attaching to the floc surface and thus avoid biofilm fouling. ${ }^{37}$ Magnetic components and coagulant components are covalently bound in MHC, which allows effective recovery of the integral structure.

\section{Conclusions}

In order to achieve rapid and advanced wastewater treatment in areas with limited space, we synthesized a novel magnetic hybrid coagulant. MHC settling time was $2 / 3$ shorter than traditional magnetic seeding coagulation. MHC improved the removal efficiency of contaminents that can be removed by traditional MSC and also efficiently removed dissovled contaminents that are difficult to remove using most conventional coagulants, especially $\mathrm{NO}_{3}{ }^{-}-\mathrm{N}$ and DON. MHC peformed well over wide ranges of initial $\mathrm{NO}_{3}{ }^{-}-\mathrm{N}$ concentration, $\mathrm{pH}$, and coexisting ions, reducing the need for costly chemical pre-treatments. Although sulfate slightly reduced $\mathrm{NO}_{3}{ }^{-}-\mathrm{N}$ removal, it has little effect on the practical water treatment porformance. The efficient $\mathrm{NO}_{3}{ }^{-}-\mathrm{N}$ removal by $\mathrm{MHC}$ stems from the electrostatic adsorption of quaternary ammonium $\mathrm{N}$ atoms, which can promote nitrate dehydration and stable adsorption to quaternary ammonium $\mathrm{N}$ atoms. The applied magnetic field can also increase the interaction potential and collision efficiency between particles to promote the combination, precipitation, and removal of dissolved water contaminents such as $\mathrm{NO}_{3}{ }^{-}-\mathrm{N}$. In addition, components of used MHC can be recovered through magnetic separation and regenerated multiple times through Donnan dialysis combined with bio-denitrification. MHC can improve the effluent water quality with a short hydraulic retention time, threreby reducing treatment footprint compared with other technologies. As such, MHC has broad application potential in the land-scarce areas for treating black odorous water bodies, secondary biological effluent, and other similar water quality challenges.

\section{Acknowledgments}

The authors are grateful for the financial support from the National Science Fund (Grant No. 21878002), the Fund for Innovative Research Group of NSFC (Grant No.51721006), the National Science Fund for Distinguished Young Scholars (Grant No. 21925801), and the Natural Science Foundation of Qinghai Science \& Technology Department in China (Grant No. 2018-ZJ-910).

\section{References}

1. Kartal, B.; Kuenen, J. G.; van Loosdrecht, M. C. M., Sewage treatment with Anammox. Science 2010, 328 (5979), 702-703.

2. Villasenor Camacho, J.; Fernandez Marchante, C. M.; Rodriguez Romero, L., Analysis of a photobioreactor scaling up for tertiary wastewater treatment: denitrification, phosphorus removal, and microalgae production. Environmental Science and Pollution Research2018, 25 (29), 29279-29286. 
3. Canfield, D. E.; Glazer, A. N.; Falkowski, P. G., The evolution and future of earth's nitrogen cycle. Science 2010, 330 (6001), 192-196.

4. Gali, A.; Dosta, J.; van Loosdrecht, M. C. M.; Mata-Alvarez, J., Biological nitrogen removal via nitrite of reject water with a SBR and chemostat SHARON/denitrification process. Industrial $\&$ Engineering Chemistry Research 2006, 45 (22), 7656-7660.

5. Bhatnagar, A.; Sillanpaa, M., A review of emerging adsorbents for nitrate removal from water. Chemical Engineering Journal2011, 168 (2), 493-504.

6. Bae, B. U.; Jung, Y. H.; Han, W. W.; Shin, H. S., Improved brine recycling during nitrate removal using ion exchange. Water Research 2002, 36 (13), 3330-3340.

7. Wang, X.; Li, M.; Song, X.; Chen, Z.; Wu, B.; Zhang, S., Preparation and evaluation of titanium-based xerogel as a promising coagulant for water/wastewater treatment. Environmental Science \& Technology2016, 50 (17), 9619-9626.

8. Zhang, M.; Xiao, F.; Wang, D.; Xu, X.; Zhou, Q., Comparison of novel magnetic polyaluminum chlorides involved coagulation with traditional magnetic seeding coagulation: Coagulant characteristics, treating effects, magnetic sedimentation efficiency and floc properties.Separation and Purification Technology 2017, $182,118-127$.

9. Zhang, M.; Xiao, F.; Xu, X. Z.; Wang, D. S., Novel ferromagnetic nanoparticle composited PACls and their coagulation characteristics. Water Research 2012, 46 (1), 127-135.

10. Shen, S.-M.; Wan, T.-J.; Shu, Y.-L., Regeneration of used magnetic seeds with ultrasound employed on the treatment of wastewater from semiconductor industry. Separation and Purification Technology2013, $108,89-95$.

11. Lv, M.; Zhang, Z.; Zeng, J.; Liu, J.; Sun, M.; Yadav, R. S.; Feng, Y., Roles of magnetic particles in magnetic seeding coagulation-flocculation process for surface water treatment.Separation and Purification Technology 2019, 212, 337-343.

12. Teh, C. Y.; Budiman, P. M.; Shak, K. P. Y.; Wu, T. Y., Recent Advancement of Coagulation-Flocculation and Its Application in Wastewater Treatment. Industrial 85 Engineering Chemistry Research 2016, 55 (16), 4363-4389.

13. Zhao, H.; Wang, L.; Hanigan, D.; Westerhoff, P.; Ni, J., Novel ion-exchange coagulants remove more low molecular weight organics than traditional coagulants. Environmental Science 85 Technology2016, 50 (7), 3897-3904.

14. Liu, J.; Cheng, S.; Cao, N.; Geng, C.; He, C.; Shi, Q.; Xu, C.; Ni, J.; DuChanois, R. M.; Elimelech, M.; Zhao, H., Actinia-like multifunctional nanocoagulant for single-step removal of water contaminants. Nature Nanotechnology 2019, 14 (1), 64-71.

15. Lee, C. T.; Yang, W. T.; Parr, R. G., Development of the colle-salvetti correlation-energy formula into a functional of the electron-density. Physical Review B 1988, 37 (2), 785-789.

16. Jorgensen, W. L.; Maxwell, D. S.; TiradoRives, J., Development and testing of the OPLS all-atom force field on conformational energetics and properties of organic liquids. Journal of the American Chemical Society 1996, 118 (45), 11225-11236.

17. Jorgensen, W. L.; Chandrasekhar, J.; Madura, J. D.; Impey, R. W.; Klein, M. L., Comparison of simple potential functions for simulating liquid water. Journal of Chemical Physics 1983, 79 (2), 926-935.

18. Moussas, P. A.; Zouboulis, A. I., A study on the properties and coagulation behaviour of modified inorganic polymeric coagulant-Polyferric silicate sulphate (PFSiS). Separation and Purification Technology 2008, 63 (2), 475-483. 
19. Sun, T.; Liu, L.-l.; Wan, L.-l.; Zhang, Y.-P., Effect of silicon dose on preparation and coagulation performance of poly-ferric-aluminum-silicate-sulfate from oil shale ash. Chemical Engineering Journal 2010, 163 (1-2), 48-54.

20. Chen, Y.; Luo, M.; Cai, W., Influence of operating parameters on the performance of magnetic seeding flocculation. Environmental Science and Pollution Research 2016, 23 (3), 2873-2881.

21. Yuan, Z.; He, C.; Shi, Q.; Xu, C.; Li, Z.; Wang, C.; Zhao, H.; Ni, J., Molecular insights into the transformation of dissolved organic matter in landfill leachate concentrate during biodegradation and coagulation processes using ESI FT-ICR MS. Environmental Science $\mathcal{E}$ Technology 2017, 51 (14), 8110-8118.

22. Mesfioui, R.; Love, N. G.; Bronk, D. A.; Mulholland, M. R.; Hatcher, P. G., Reactivity and chemical characterization of effluent organic nitrogen from wastewater treatment plants determined by Fourier transform ion cyclotron resonance mass spectrometry. Water Research 2012, 46 (3), 622-634.

23. Opsahl, S.; Benner, R., Distribution and cycling of terrigenous dissolved organic matter in the ocean. Nature 1997, 386 (6624), 480-482.

24. Hertkorn, N.; Benner, R.; Frommberger, M.; Schmitt-Kopplin, P.; Witt, M.; Kaiser, K.; Kettrup, A.; Hedges, J. I., Characterization of a major refractory component of marine dissolved organic matter.Geochimica Et Cosmochimica Acta 2006, 70 (12), 2990-3010.

25. Doxtader, K. G.; Alexander, M., Nitrification by heterotrophic soil microorganisms. Soil Science Society of America Proceedings1966, 30 (3), 351-355.

26. Delwiche, C. C., Biological transformations of nitrogen compounds.Industrial and Engineering Chemistry 1956, 48 (9), 1421-1427.

27. Kiriukhin, M. Y.; Collins, K. D., Dynamic hydration numbers for biologically important ions. Biophysical Chemistry 2002,99 (2), 155-168.

28. Nightingale, E. R., Phenomenological theory of ion solvation - effective radii of hydrated ions. Journal of Physical Chemistry1959, 63 (9), 1381-1387.

29. Gao, Q.; Wang, C.-Z.; Liu, S.; Hanigan, D.; Liu, S.-T.; Zhao, H.-Z., Ultrafiltration membrane microreactor (MMR) for simultaneous removal of nitrate and phosphate from water. Chemical Engineering Journal2019, 355, 238-246.

30. K, T.; Tadesse, N.; Rt, C.; Alemaw, B.; Laletsang, K., Impacts of Treated Wastewater on the Surface Water and Groundwater Quality: A Case Study in North East Gaborone, Botswana. Asian Review of Environmental and Earth Sciences 2017, 4, 36-45.

31. Suthar, S.; Sharma, J.; Chabukdhara, M.; Nema, A. K., Water quality assessment of river Hindon at Ghaziabad, India: impact of industrial and urban wastewater. Environmental Monitoring and Assessment2010, 165 (1-4), 103-112.

32. Marcus, Y., Thermodynamics of solvation of ions .5. Gibbs free-energy of hydration at 298.15 K. Journal of the Chemical Society-Faraday Transactions 1991, 87 (18), 2995-2999.

33. Custelcean, R.; Moyer, B. A., Anion separation with metal-organic frameworks. European Journal of Inorganic Chemistry2007, 10 (10), 1321-1340.

34. Lisjak, D.; Mertelj, A., Anisotropic magnetic nanoparticles: A review of their properties, syntheses and potential applications.Progress in Materials Science 2018, 95, 286-328.

35. Baebler, M. U., A collision efficiency model for flow-induced coagulation of fractal aggregates. Aiche Journal 2008,54 (7), 1748-1760.

36. Zhao, B.; Zhao, H.; Ni, J., Modeling of the Donnan dialysis process for arsenate removal. Chemical Engineering Journal 2010,160 (1), 170-175. 
37. Ebrahimi, S.; Roberts, D. J., Bioregeneration of single use nitrate selective ion-exchange resin enclosed in a membrane: Kinetics of desorption. Separation and Purification Technology 2015,146, 268-275.

38. MOEP, Environmental Statistics Bulletin - Various Years. China, M. o. E. P. o. t. P. s. R. o., Ed. Beijing, China, 2017-2018.

\section{FIGURE CAPTIONS}

Figure 1. Schematic illustration showing the structure, coagulation and regeneration of MHC.

Figure 2. Synthesis and structure of MHC.

Figure 3. TEM images of MHC (a) and $\mathrm{Fe}_{3} \mathrm{O}_{4}$ (b), and FT-IR spectra (c) of $\mathrm{MHC}$ and $\mathrm{Fe}_{3} \mathrm{O}_{4}$. Scale bars, $50 \mathrm{~nm}$.

Figure 4. Turbidity (a), $\mathrm{UV}_{254}$ (b), TP (c) and $\mathrm{NO}_{3}{ }^{-} \mathrm{N}$ (d) removal after the coagulation of the secondary biological effluent using MHC and MSC as a function of settling time with coagulant dosage of $0.8 \mathrm{mmol} / \mathrm{L}$ as total Fe and PAM dosage in MSC is $0.4 \mathrm{mg} / \mathrm{L}$.

Figure 5. The relative abundance of CHO, CHON, CHOS, and CHONS in the raw water and MHC coagulated water (a). Van Krevelen diagrams of CHON of the raw water (b) and MHC coagulated water (c) with dosage of $0.8 \mathrm{mmol} / \mathrm{L}$ as total Fe. Colored dots express the relative abundance. The black lines in Van Krevelen diagrams divide $\mathrm{CHON}$ to seven major classes. The bar diagram shows the relative abundance of seven classes of CHON in the raw water and MHC coagulated water (d).

Figure 6. Effect of initial $\mathrm{NO}_{3}{ }^{-} \mathrm{N}$ concentration (a), $\mathrm{pH}$ (b), and ions (c) on the removal of $\mathrm{NO}_{3}{ }^{-}$and selectivity coefficient of $\mathrm{NO}_{3}{ }^{-}$to phosphate and sulfate (d). MHC dose in c and d was $0.8 \mathrm{mmol} / \mathrm{L}$ as total Fe.

Figure 7. Interaction energy between $\mathrm{NO}_{3}{ }^{-}$and $\mathrm{N}$ atom of quaternary ammonium group at different relative positions (a). Nitrate positions during removal categorized by total interaction potential (b). Van der Waals and electrostatic interaction energy between nitrate and $\mathrm{MHC}$ (c). Number of $\mathrm{H}$ bonds between $\mathrm{NO}_{3}{ }^{-}$ and coordinating water molecules during removal process (d). Snapshots of nitrate removal pathway by quaternary ammonium groups (e). $\mathrm{O}$, red; $\mathrm{N}$, dark blue; $\mathrm{H}$, gray; $\mathrm{C}$, green. Methyl group $\mathrm{C}$ atoms on quaternary ammonium $\mathrm{N}$ atoms in (a) were highlighted in light blue.

Figure 8. Nitrate removal using MHC with and without magnetic field (a). The MATLAB simulation of interaction potential energy between magnetic particles under different magnetic field strengths (b). The parameters used in the modeling process are in Table S3, and the raw water quality is shown in Table S2.

Figure 9. MHC regeneration process schematic (a). $\mathrm{NO}_{3}{ }^{-}-\mathrm{N}$ concentration variations in the desorption solution (b) and stripping solution (c) during regeneration. Nitrate removal after repeated MHC regeneration (d).

\section{Hosted file}

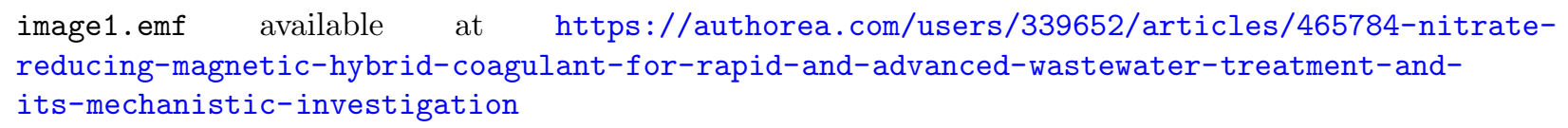

Figure 1. Schematic illustration showing the structure, coagulation and regeneration of MHC.

\section{Hosted file}

image2.emf available at https://authorea.com/users/339652/articles/465784-nitratereducing-magnetic-hybrid-coagulant-for-rapid-and-advanced-wastewater-treatment-andits-mechanistic-investigation

Figure 2. Synthesis and structure of MHC. 


\section{Hosted file}

image3.emf available at https://authorea.com/users/339652/articles/465784-nitratereducing-magnetic-hybrid-coagulant-for-rapid-and-advanced-wastewater-treatment-andits-mechanistic-investigation

Figure 3. TEM images of MHC (a) and $\mathrm{Fe}_{3} \mathrm{O}_{4}$ (b), and FT-IR spectra (c) of MHC and $\mathrm{Fe}_{3} \mathrm{O}_{4}$. $\mathrm{Scale}_{\text {bars, }}$ $50 \mathrm{~nm}$.

\section{Hosted file}

image4.emf available at https://authorea.com/users/339652/articles/465784-nitratereducing-magnetic-hybrid-coagulant-for-rapid-and-advanced-wastewater-treatment-andits-mechanistic-investigation

Figure 4. Turbidity (a), $\mathrm{UV}_{254}$ (b), $\mathrm{TP}$ (c) and $\mathrm{NO}_{3}{ }^{-}-\mathrm{N}$ (d) removal after the coagulation of the secondary biological effluent using $\mathrm{MHC}$ and $\mathrm{MSC}$ as a function of settling time with coagulant dosage of $0.8 \mathrm{mmol} / \mathrm{L}$ as total Fe and PAM dosage in MSC is $0.4 \mathrm{mg} / \mathrm{L}$.

\section{Hosted file}

image5.emf available at https://authorea.com/users/339652/articles/465784-nitratereducing-magnetic-hybrid-coagulant-for-rapid-and-advanced-wastewater-treatment-andits-mechanistic-investigation

Figure 5. The relative abundance of CHO, CHON, CHOS, and CHONS in the raw water and MHC coagulated water (a). Van Krevelen diagrams of CHON of the raw water (b) and MHC coagulated water (c) with dosage of $0.8 \mathrm{mmol} / \mathrm{L}$ as total Fe. Colored dots express the relative abundance. The black lines in Van Krevelen diagrams divide $\mathrm{CHON}$ to seven major classes. The bar diagram shows the relative abundance of seven classes of $\mathrm{CHON}$ in the raw water and $\mathrm{MHC}$ coagulated water $(\mathrm{d})$.

\section{Hosted file}

image6.emf available at https://authorea.com/users/339652/articles/465784-nitratereducing-magnetic-hybrid-coagulant-for-rapid-and-advanced-wastewater-treatment-andits-mechanistic-investigation

Figure 6. Effect of initial $\mathrm{NO}_{3}^{-}-\mathrm{N}$ concentration (a), $\mathrm{pH}(\mathrm{b})$, and ions (c) on the removal of $\mathrm{NO}_{3}^{-}$and selectivity coefficient of $\mathrm{NO}_{3}^{-}$to phosphate and sulfate (d). MHC dose in c and d was $0.8 \mathrm{mmol} / \mathrm{L}$ as total Fe.

\section{Hosted file}

image7.emf available at https://authorea.com/users/339652/articles/465784-nitratereducing-magnetic-hybrid-coagulant-for-rapid-and-advanced-wastewater-treatment-andits-mechanistic-investigation

Figure 7. Interaction energy between $\mathrm{NO}_{3}{ }^{-}$and $\mathrm{N}$ atom of quaternary ammonium group at different relative positions (a). Nitrate positions during removal categorized by total interaction potential (b). Van der Waals

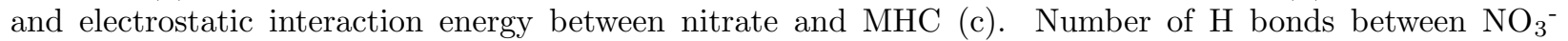
and coordinating water molecules during removal process (d). Snapshots of nitrate removal pathway by quaternary ammonium groups (e). O, red; N, dark blue; H, gray; C, green. Methyl group C atoms on quaternary ammonium $\mathrm{N}$ atoms in (a) were highlighted in light blue.

\section{Hosted file}

image8.emf available at https://authorea.com/users/339652/articles/465784-nitratereducing-magnetic-hybrid-coagulant-for-rapid-and-advanced-wastewater-treatment-andits-mechanistic-investigation 
Figure 8. Nitrate removal using MHC with and without magnetic field (a). The MATLAB simulation of interaction potential energy between magnetic particles under different magnetic field strengths (b). The parameters used in the modeling process are in Table S3, and the raw water quality is shown in Table S2.

\section{Hosted file}

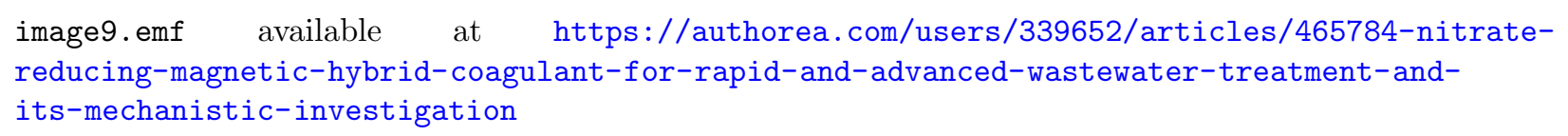

Figure 9. $\mathrm{MHC}$ regeneration process schematic (a). $\mathrm{NO}_{3}{ }^{-}-\mathrm{N}$ concentration variations in the desorption solution (b) and stripping solution (c) during regeneration. Nitrate removal after repeated MHC regeneration (d). 